\title{
Effect of High-Flow Nasal Cannula and Body Position on End-Expiratory Lung Volume: A Cohort Study Using Electrical Impedance Tomography
}

\author{
Jordi Riera MD, Purificación Pérez MD, Jordi Cortés, Oriol Roca MD PhD, \\ Joan Ramon Masclans MD PhD, and Jordi Rello MD PhD
}

\begin{abstract}
BACKGROUND: Electrical impedance tomography measures changes in lung impedance, which are mainly related to changes in lung volume. We used electrical impedance tomography to investigate the effects of high-flow nasal cannula (HFNC) and body position on global and regional end-expiratory lung impedance variation ( $\triangle$ EELI). METHODS: Prospective study with 20 healthy adults. Two periods were defined: the first in supine position and the second in prone position. Each period was divided into 3 phases. In the first and the third phases the subjects were breathing ambient air, and in the second HFNC was implemented. Four regions of interest were defined: 2 ventral and 2 dorsal. For each respiratory cycle, global and regional $\triangle E E L I$ were measured by electrical impedance tomography and were expressed as a function of the tidal variation of the first stable respiratory cycle (units). RESULTS: HFNC increased global EELI by 1.26 units (95\% CI $1.20-1.31, P<.001)$ in supine position, and by 0.87 units $(95 \%$ CI $0.82-0.91, P<.001)$ in prone position. The distribution of $\triangle E E L I$ was homogeneous in prone position, with no difference between ventral and dorsal lung regions $(-0.01$ units, $95 \% \mathrm{CI}-0.01$ to $0, P=.18)$, while in supine position a significant difference was found $(0.22$ units, $95 \%$ CI $0.21-0.23, P<.001)$ with increased EELI in ventral areas. CONCLUSIONS: HFNC increased global EELI in our population, regardless of body position, suggesting an increase in functional residual capacity. Prone positioning was related to a more homogeneous distribution of $\triangle E E L I$, while in supine position $\triangle E E L I$ was higher in the ventral lung regions. Key words: high-flow nasal cannula; electrical impedance tomography; body position; lung volume; oxygen therapy; prone position. [Respir Care 2013;58(4):589-596. @ 2013 Daedalus Enterprises]
\end{abstract}

All men by nature desire to know.

$$
\text { -Aristotle, Metaphysics }
$$

Introduction

High-flow nasal cannula (HFNC) has been described as an excellent method of noninvasive oxygen delivery. In

\footnotetext{
The authors are affiliated with the Critical Care Department, Vall d'Hebron Research Institut, Vall d'Hebron University Hospital, Universitat Autònoma de Barcelona, Barcelona, Spain, with the exception of Mr Cortés, who is affiliated with the Department of Statistics and Operations Research, Universitat Politècnica de Catalunya, Barcelona, Spain. Drs Roca, Masclans, and Rello are also affiliated with Centro de Investigación Biomédica en Red Enfermedades Respiratorias, Instituto de Salud Carlos III, Madrid, Spain.
}

adult patients, warmed and humidified air can be delivered at up to $50 \mathrm{~L} / \mathrm{min}$, thus achieving a decrease in oxygen dilution, ${ }^{1-3}$ a reduction of respiratory dead space, ${ }^{2,4}$ and the

\footnotetext{
Dr Riera presented a version of this paper at the 25th Annual Congress of the European Society of Intensive Care Medicine, held October 13-17, 2012, in Lisbon, Portugal.

Drs Masclans and Roca have disclosed relationships with Fisher \& Paykel. The other authors have disclosed no conflicts of interest.

Correspondence: Jordi Riera MD, Critical Care Department, Vall d'Hebron Research Institut, Vall d'Hebron University Hospital, Universitat Autònoma de Barcelona, Paseo Vall d'Hebron 119-129, 08035 Barcelona, Spain. E-mail: jorriera@ vhebron.net.
}

DOI: $10.4187 /$ respcare. 02086 
generation of a certain degree of positive airway pressure. . $^{2,3-5-8}$ This therapy is very well tolerated by patients with acute respiratory failure ${ }^{9-14}$ and has become a highly effective noninvasive oxygen delivery device in adults as well as children. ${ }^{15-17}$ The possible mechanisms underlying this high efficacy of HFNC have been discussed, ${ }^{4,18}$ but, to our knowledge, only one recent published study has explored the effects of the therapy on lung volumes. ${ }^{19}$

Prone positioning is a maneuver that improves oxygenation and respiratory mechanics in mechanically ventilated patients with acute lung injury $20-23$ and may reduce mortality in patients with severe hypoxemia. ${ }^{24}$ The effects of this therapy on regional lung ventilation have been described in non-intubated healthy adult subjects ${ }^{25}$ and in preterm infants on CPAP, ${ }^{26}$ but its impact on lung volume distribution in adult subjects with HFNC therapy has not been discussed to date.

Electrical impedance tomography (EIT) is a noninvasive, non-ionizing, bedside method of monitoring bioimpedance changes related to different lung conditions, especially those related to regional ventilation. ${ }^{27-29}$ Interestingly, good correlations have been found between changes in end-expiratory lung impedance (EELI) and changes in end-expiratory lung volume (EELV), ${ }^{30,31}$ which is equivalent to functional residual capacity in nonintubated subjects. Another important feature of EIT is the possibility of assessing regional changes of impedance. The technique has been used to evaluate the local dynamic behavior of the lung in spontaneously breathing healthy subjects. ${ }^{25,32}$ Thus, EIT can provide information in a noninvasive manner about the changes in global and regional EELI associated with HFNC application in 2 different body positions.

\section{See the Related Editorial on Page 715}

The primary aims of this study were to compare the variation of global EELI associated with the high-flow application and to evaluate the influence of supine and prone position in regional impedance distribution. As a secondary aim, changes in breathing frequency between the different conditions were also measured, in view of the reports of a trend toward a decrease in the breathing frequency when HFNC is implemented.1,2,11-13,25

\section{Methods}

The study was conducted at the critical care department of the tertiary University Hospital of Vall d'Hebron in Barcelona. The study was approved by the ethics committee on January 10, 2011 (reference PR_AG_210-2010). Written informed consent was obtained from all subjects prior to the study.

\section{QUICK LOOK}

\section{Current knowledge}

Heat and humidification of high-flow oxygen via nasal cannula improves patient comfort and allows the cannula to serve as a high-flow oxygen system. The impact of high nasal flow on airway pressures and endexpiratory lung volume remains unsettled.

\section{What this paper contributes to our knowledge}

High-flow oxygen via nasal cannula in healthy subjects increased the end-expiratory lung volume and reduced the breathing frequency in both the supine and prone positions. Prone positioning resulted in more even distribution of end-expiratory lung volume in normal subjects.

\section{Subjects}

Twenty healthy volunteers were recruited. Exclusion criteria were age below 18 years, pregnancy, clinical evidence of respiratory illness, history of respiratory disease, body mass index over $50 \mathrm{~kg} / \mathrm{m}^{2}$, and ribcage malformation. Height, weight, body mass index, and chest circumference were measured.

\section{High-Flow Nasal Cannula Application}

Totally conditioned medical air $\left(\mathrm{F}_{\mathrm{IO}_{2}} 0.21\right)$ was delivered via HFNC (Optiflow, Fisher \& Paykel Healthcare, Auckland, New Zealand) at a constant flow of $40 \mathrm{~L} / \mathrm{min}$. The humidifier (MR850, Fisher \& Paykel Healthcare, Auckland, New Zealand) temperature was set to $37^{\circ} \mathrm{C}$, and the air was delivered by silicon, medium sized nasal cannulae (RT050/051, Fisher \& Paykel Healthcare, Auckland, New Zealand). Subjects were asked to breathe with mouth closed.

\section{Electrical Impedance Tomography Measurement}

EIT has been described as a reliable method of monitoring pulmonary ventilation. The technique uses injection of high frequency and low amplitude electrical currents through 16 electrodes around the thorax to generate crosssectional images of the subject. Images of electrical impedance distribution are obtained from the resulting potential differences measured in the electrodes on the surface of the chest wall using a reconstruction algorithm. In the present study, EIT measurements were performed with the Pulmovista tomograph (Dräger Medical, Lübeck, Germany). The size of the rubber belt bearing the electrodes 


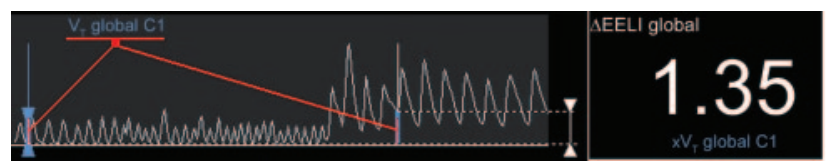

Fig. 1. As electrical impedance tomography measures variation of impedance values, a reference is needed to express the magnitude of the changes. The end-expiratory lung impedance variation $(\triangle \mathrm{EELI})$ of each respiratory cycle is expressed as a function of the tidal variation of the first stable respiratory cycle (VT global C1) of the first phase.

was selected according to the chest circumference measurement. The contact surface of the electrodes was wetted with alcohol. The belt was applied between the 4th and the 6th intercostal space. Self-test calibration was made by the system. Resistivity of each electrode was assessed. A high signal quality was necessary to start the measurements. The position of the subject was not changed during the period of measurement, because this might have caused changes in impedance unrelated to the maneuvers under study. A stable breath pattern was needed to start the study. The impedance variation was evaluated during each phase. The system measured the impedance changes of the thorax slide, which was divided into 4 regions of interest: rightventral (region 1), left-ventral (region 2), right-dorsal (region 3), and left-dorsal (region 4). As impedance measurements are relative, a reference was needed to quantify the magnitude of the changes. The EELI variation ( $\triangle$ EELI) of each respiratory cycle is expressed as a function of the tidal variation of the first stable respiratory cycle (units) of the first phase (Fig. 1).

\section{Study Procedures}

Two different study periods were defined and performed on 2 different days, each one divided into 3 phases. First, the subjects were assessed in supine position, breathing with the mouth closed. The electrical impedance tomograph was applied. After 2 min breathing ambient air, HFNC was applied for 4 min. Finally, another 2-min phase breathing ambient air completed this first study period. In each phase, global and regional $\triangle$ EELI were measured as previously described. Since the clinical effects of HFNC are usually immediate and maintained over time, we designed the study with short exposure periods of time. Breathing frequency was also recorded. The same subjects were assessed in the second period of the study, this time assessed in prone position, breathing with the mouth closed. The period was also divided into the 3 phases described above. Global and regional $\triangle E E L I$ and breathing frequency measurements were made. Means of global and regional $\Delta$ EELI in each phase were compared.

\section{Statistical Analysis}

The values are presented as mean $\pm \mathrm{SD}$. A mixed-effect regression model was used to assess the mean changes in EELI. An unstructured covariance matrix was used to describe the repeated measures in each subject. Changes in breathing frequency (only one determination per subject, phase, and period) were estimated with a paired $t$ test, and we report the $95 \%$ confidence intervals for the differences. Significance was set at a 2 -tailed $P$ value of .05 . All analyses were performed using statistical software (R 11.1, R Foundation for Statistical Computing, Vienna, Austria).

\section{Results}

The characteristics of the 20 healthy volunteers are shown in the Table. There were major difficulties in obtaining a correct EIT signal in subject 11 because of incorrect belt fitting, so the data derived were not included in the analysis. Subject 14 was unable to be contacted during the second period of the study. No adverse effects were observed during HFNC use.

There were $41.02 \pm 15.97$ measurements of $\Delta$ EELI per subject in the first period of the study, with subjects breathing in supine position, and $30.63 \pm 11.84$ measurements in the second period of the study, with subjects breathing in prone position.

\section{Global $\Delta$ EELI}

In supine position, HFNC increased global EELI by 1.26 units (95\% CI 1.20-1.31, $P<.001$ ), compared to the first phase of ambient air breathing. Comparing the second phase and the third (ambient air breathing), there was a significant decrease in global EELI $(1.30,95 \%$ CI 1.25 1.35, $P<.001$ ) (Fig. 2).

In prone position, similar changes in global $\triangle E E L I$ with HFNC were observed. During the HFNC phase an increase in global EELI of 0.87 units (95\% CI 0.82-0.91, $P<.001$ ) was observed. Moreover, a decrease of 1.03 units (95\% CI $0.98-1.08, P<.001$ ) was found between the second HFNC phase and the third ambient air phase (see Fig. 2).

\section{Regional $\Delta$ EELI}

In supine position, higher values of regional EELI were observed in the ventral lung regions (Fig. 3), comparing the first ambient air phase and the HFNC phase. Comparing the $\triangle$ EELI of these ventral areas (region 1 and region 2) with the $\triangle$ EELI of the dorsal areas (region 3 and region 4), a significant difference was found ( 0.22 units, 95\% CI 0.21-0.23, $P<.001$, Fig. 4). 
Table. Characteristics of the Population

\begin{tabular}{|c|c|c|c|c|c|c|c|c|}
\hline \multirow{2}{*}{$\begin{array}{l}\text { Subject } \\
\text { Number }\end{array}$} & \multirow{2}{*}{$\begin{array}{c}\text { Sex } \\
(12 \mathrm{M}, 8 \mathrm{~F})\end{array}$} & \multirow{2}{*}{$\begin{array}{l}\text { Age } \\
\text { (y) }\end{array}$} & \multirow{2}{*}{$\begin{array}{l}\text { Height } \\
(\mathrm{cm})\end{array}$} & \multirow{2}{*}{$\begin{array}{l}\text { Weight } \\
(\mathrm{kg})\end{array}$} & \multirow{2}{*}{$\begin{array}{l}\text { Body Mass Index } \\
\left(\mathrm{kg} / \mathrm{m}^{2}\right)\end{array}$} & \multirow{2}{*}{$\begin{array}{c}\text { Basal } \\
\text { Breathing } \\
\text { Frequency } \\
\text { (breaths/min) }\end{array}$} & \multicolumn{2}{|c|}{ Thorax Perimeter (cm) } \\
\hline & & & & & & & Inspiration & Expiration \\
\hline 1 & M & 31 & 184 & 85 & 25.1 & 15.5 & 106 & 98 \\
\hline 2 & M & 40 & 180 & 77 & 23.8 & 13 & 99 & 93 \\
\hline 3 & M & 26 & 176 & 70 & 22.6 & 18.5 & 93 & 89 \\
\hline 4 & M & 34 & 178 & 59 & 18.6 & 19 & 88 & 80 \\
\hline 5 & M & 24 & 185 & 81 & 23.7 & 15.5 & 98 & 94 \\
\hline 6 & M & 30 & 174 & 72 & 23.8 & 13 & 98 & 93 \\
\hline 7 & M & 57 & 169 & 64 & 22.4 & 21 & 97 & 95 \\
\hline 8 & M & 26 & 172 & 72 & 24.3 & 18 & 99 & 95 \\
\hline 9 & M & 37 & 169 & 68 & 23.8 & 13.5 & 98 & 94 \\
\hline 10 & M & 24 & 182 & 72 & 21.7 & 14 & 95 & 90 \\
\hline 11 & F & 28 & 174 & 66 & 21.8 & 16 & 94 & 89 \\
\hline 12 & M & 27 & 173 & 68 & 22.7 & 11.5 & 93 & 89 \\
\hline 13 & M & 25 & 186 & 93 & 26.9 & 7 & 103 & 99 \\
\hline 14 & F & 32 & 164 & 55 & 20.4 & 20.5 & 84 & 76 \\
\hline 15 & $\mathrm{~F}$ & 28 & 158 & 53 & 21.2 & 9 & 84 & 78 \\
\hline 16 & $\mathrm{~F}$ & 29 & 159 & 58 & 22.9 & 11 & 88 & 83 \\
\hline 17 & $\mathrm{~F}$ & 26 & 180 & 68 & 21 & 16.5 & 88 & 83 \\
\hline 18 & $\mathrm{~F}$ & 26 & 158 & 50 & 20 & 13.5 & 80 & 74 \\
\hline 19 & F & 27 & 172 & 57 & 19.3 & 19 & 74 & 68 \\
\hline 20 & $\mathrm{~F}$ & 28 & 169 & 62 & 21.7 & 9 & 88 & 81 \\
\hline Mean \pm SD & & $30.2 \pm 7.5$ & $173.1 \pm 8.6$ & $67.5 \pm 10.9$ & $90.2 \pm 0.7$ & $14.08 \pm 4.5$ & $92.3 \pm 8.0$ & $87.0 \pm 8.6$ \\
\hline
\end{tabular}
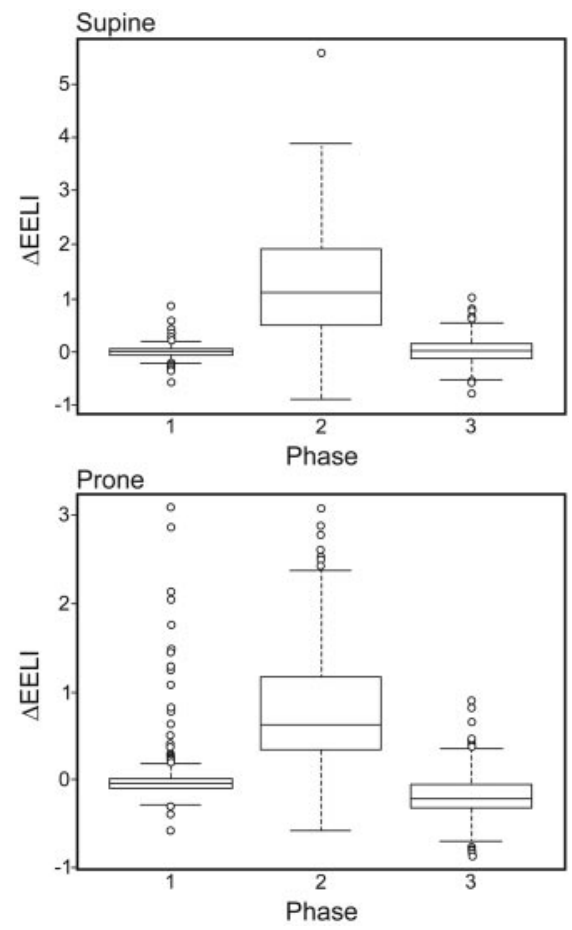

Fig. 2. Global end-expiratory lung impedance variation ( $\Delta E E L I)$ in the supine and prone positions while breathing ambient air (phases 1 and 3) versus on high-flow nasal cannula (phase 2). $\triangle \mathrm{EELI}$ is higher during the ambient air phases.
A more homogeneous pattern of regional EELI variation was observed in prone position, with a lower increase in EELI in the ventral regions (Fig. 5). In this position, no significant differences in $\triangle$ EELI were evidenced when comparing ventral and dorsal areas ( -0.01 units, 95\% CI $-0.01,0, P=.18$ ) (Fig. 6).

\section{Breathing Frequency}

A decrease in the breathing frequency was observed between the first and the second phases in both periods. In the supine position there was a mean decrease of 2.73 breaths $/ \mathrm{min}(95 \% \mathrm{CI} 0.4-5.08, P=.02)$. In the prone position a mean decrease of 7.89 breaths/min $(95 \% \mathrm{CI}$ $4.38-11.4, P<.001$ ) was observed. In the supine position there was no significant difference in breathing frequency between the second (HFNC) and the third (ambient air) phases $(0.10$ breaths $/ \mathrm{min}, 95 \% \mathrm{CI}-2.17$ to $2.38, P=.92)$, but in prone position the breathing frequency of the third phase was 2.22 breaths $/ \mathrm{min}(95 \% \mathrm{CI} 0.83-3.61, P=.003)$, higher than the second phase.

\section{Discussion}

These data demonstrate that the noninvasive application of HFNC increases EELI in healthy subjects, suggesting 

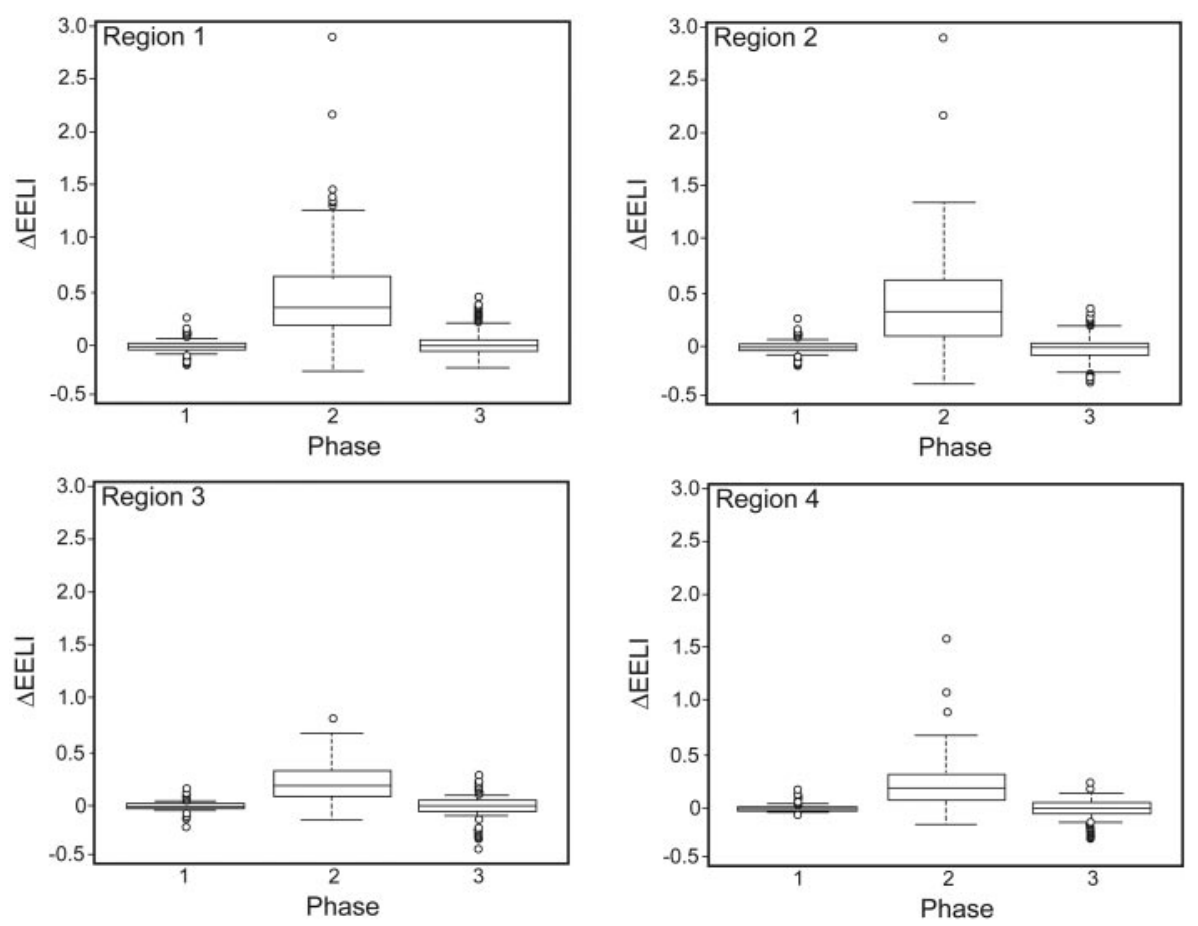

Fig. 3. Regional end-expiratory lung impedance variation ( $\Delta \mathrm{EELI})$ in the supine position. Regional $\Delta \mathrm{EELI}$ is higher in the ventral regions (1 and 2).
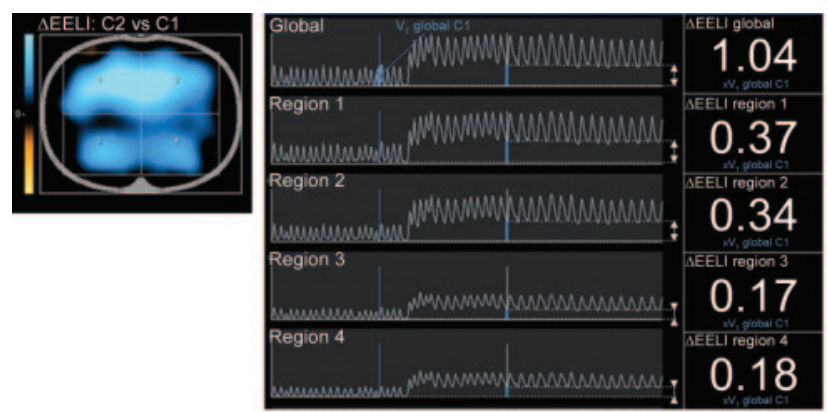

Fig. 4. Image, curves, and numbers of global and regional endexpiratory lung impedance variation ( $\Delta E E L I)$ of a subject breathing in supine position. There is a substantial difference between the ventral ( 1 and 2 ) and dorsal (3 and 4 ) lung regions.

an increase in the functional residual capacity. This increase is significantly higher in the ventral lung regions when the subject is breathing in supine position; the distribution is more homogeneous when breathing in the prone position. To our knowledge, this is the first study reporting the effects of body position in impedance distribution in subjects with high-flow therapy. Furthermore, we also observed a decrease in the breathing frequency associated with the HFNC application.

There was a significant increase in global EELI, comparing breathing ambient air and breathing with HFNC, in both supine and prone positions. A good correlation has been previously demonstrated between changes in lung impedance measured by EIT and changes in lung volume, ${ }^{30,33-37}$ suggesting that the application of high-flow therapy could increase functional residual capacity. This finding was already reported in a recent study, ${ }^{19}$ where HFNC significantly increased global EELI in a population of post-cardiac surgery patients with respiratory dysfunction. This effect is reversible, given that significant differences between the second phase (HFNC) and the third phase (ambient air) were observed. This increment of global EELI could be explained by the previously demonstrated generation of positive airway pressure when HFNC is applied $^{2,3,5-8,19}$ In fact, a strong and significant correlation between airway pressure and EELI during HFNC use has been recently described. ${ }^{19}$ This positive airway pressure achieved correlates with flow administered, being up to $7 \mathrm{~cm}$ of $\mathrm{H}_{2} \mathrm{O}$ with $50 \mathrm{~L} / \mathrm{min}^{2,7}$ There are more outlier values observed in the HFNC measurements, regardless of body position (see Fig. 2). These outliers match with the first measurements done in the second phase. When the HFNC system is applied, it takes a few respiratory cycles to reach a stable breath pattern.

We demonstrated a significant difference in the distribution of the $\triangle$ EELI when comparing the application of HFNC in supine and prone position. In supine position the regional $\triangle$ EELI of the ventral regions of the lung parenchyma was significantly higher than the regional $\Delta$ EELI of the dorsal regions. This fact was not observed when the subject was in prone position, in which $\Delta$ EELI distribution 

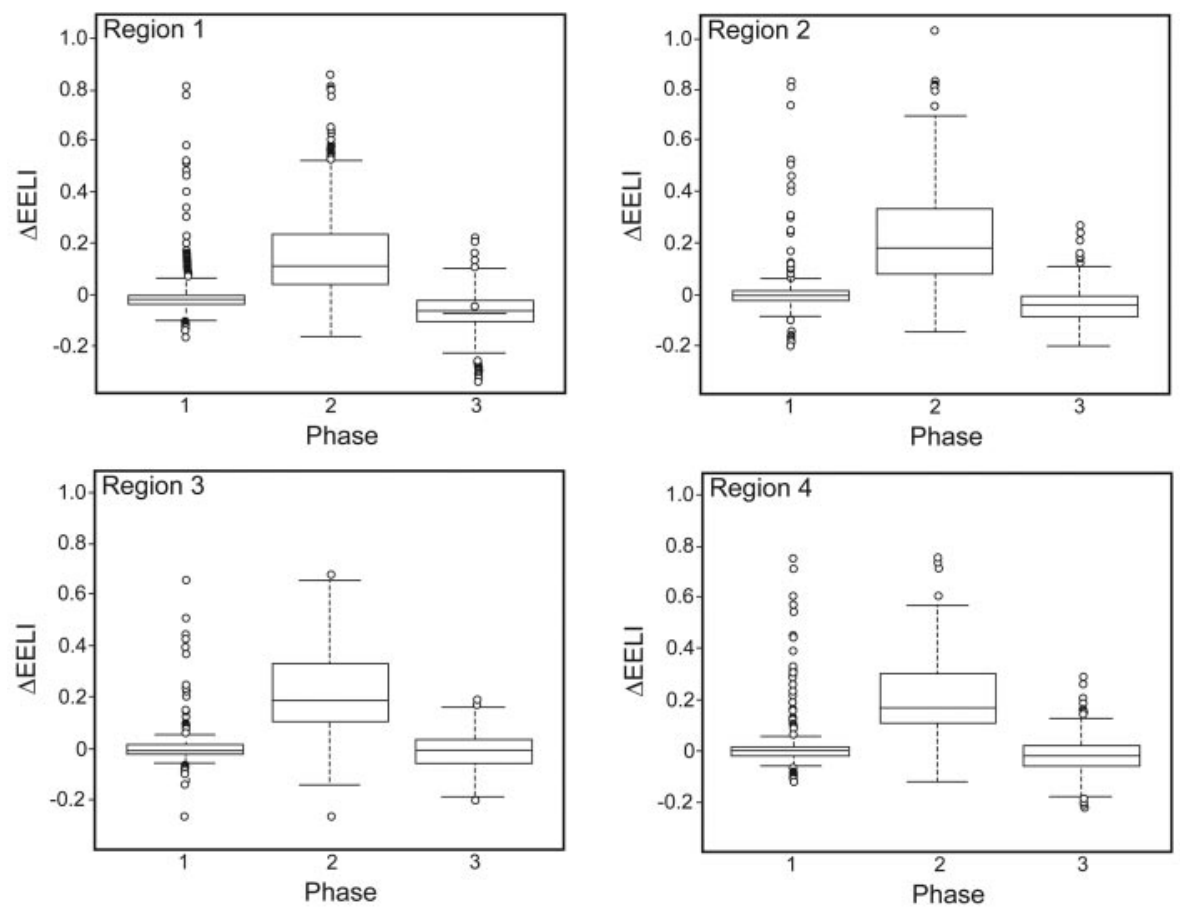

Fig. 5. Regional end-expiratory lung impedance variation ( $\Delta \mathrm{EELI})$ in the prone position. Note the more homogeneous $\Delta \mathrm{EELI}$ distribution.
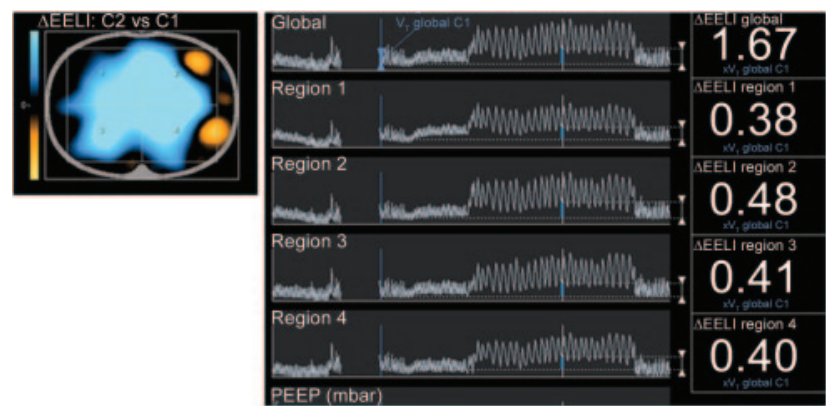

Fig. 6. Image, curves, and numbers of global and regional endexpiratory lung impedance variation ( $\triangle E E L L I)$ in the prone position. Note the more homogeneous $\Delta$ EELI distribution.

is more homogeneous. This finding is consistent with a previous report on prone positioning in ARDS-affected mechanically ventilated patients. ${ }^{38}$ In these patients, prone position may induce a more homogeneous distribution of transpulmonary pressure, and hence of alveolar inflation, although patients' conditions could be different from those of our population. Diaphragm movement in spontaneously breathing subjects plays an essential role in alveolar inflation distribution, a condition that is usually minimized with mechanically ventilated patients in prone position.

Riedel and co-workers assessed the effect of prone positioning with EIT in spontaneously breathing subjects, where a continuous positive airway pressure (CPAP) was applied, ${ }^{25}$ observing that in supine position ventilation in the dorsal regions remained unchanged from 0 to $10 \mathrm{~cm} \mathrm{H}_{2} \mathrm{O}$
CPAP, but increased in the ventral areas, while in prone position the ventral regions showed reduced ventilation at $10 \mathrm{~cm} \mathrm{H}_{2} \mathrm{O}$ CPAP. This tendency toward a more heterogeneous ventilation pattern in the supine position was also demonstrated in an animal model ventilated with a PEEP of $10 \mathrm{~cm} \mathrm{H}_{2} \mathrm{O}$, while ventilating in prone position eliminated the dorsal-to-ventral gradient. ${ }^{39}$ All these results are consistent with our findings, as we noted a higher EELI increase in the non-dependent lung regions in the supine position than in the dependent regions. This homogeneity of air distribution may be of interest in hypoxemic patients, in whom prone positioning could improve the oxygenation efficacy of the high-flow oxygen therapy, since it has been suggested that response in $\mathrm{P}_{\mathrm{aO}_{2}}$ is associated with a more homogeneous regional inflation. ${ }^{40}$ Furthermore, better oxygenation has been recently described as a predictor of HFNC treatment success. ${ }^{12}$

These findings in healthy subjects, if confirmed in hypoxemic patients, would be of interest in high-flow treatment. Prone positioning in this population could improve oxygen therapy efficacy. However, 2 issues should be assessed in hypoxemic patients. First, tolerability of the prone position of patients with a high work of breathing, and, second, the consequences of this more homogeneous pattern on gas exchange and on alveolar stress and strain in the injured lung. Moreover, the degree of alveolar recruitability of HFNC therapy could change, depending on the lung pathology. It would also be interesting to evaluate the relationship between the magnitude of this EELI in- 
crease and the degree of the associated clinical changes. For this purpose, the $\Delta$ EELI/ $\Delta$ lung volume relation should be calculated with a nitrogen wash-out maneuver. ${ }^{30}$ These questions should be examined on further investigations that could contribute to the growing body of information regarding HFNC therapy.

A significant decrease in the breathing frequency was observed when HFNC was implemented, in both body positions. This finding is consistent with results observed in previous studies that included patients with acute respira-

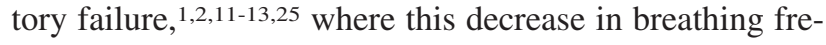
quency was not associated with hypercapnic acidosis. ${ }^{11-13}$ Different reasons may explain these results. The first explanation that may partially explain this fact is the reduction of the anatomic dead space generated by the continuous administration of high flow of gas, known as washout effect. ${ }^{2,4,18}$ More importantly, the reduction in breathing frequency may be a consequence of an increase in tidal volume. In this sense, a similar decrease in breathing frequency and an increase in tidal volume inferred by the tidal impedance variation when HFNC was applied have been previously reported. ${ }^{19}$

Our study has certain limitations. Some are inherent to the EIT technique. We estimated changes in EELV by changes in EELI. Bikker et al found that this correlation was significant but relatively low $\left(r=0.79, R^{2}=0.62\right) .{ }^{41}$ However, in this study a PEEP trial was performed, so potential thorax geometry changes and craniocaudal thorax structure movements could distort $\Delta$ impedance measurements. On the other hand, Erlandsson et al found good agreement between tidal impedance variation and tidal volume $\left(\mathrm{R}^{2}=0.95\right),{ }^{42}$ Richard et al validated EIT as a regional lung ventilation monitor by positron-emission tomography in healthy individuals with a coefficient of determination of $0.63,{ }^{37}$ and Hinz et al also described good agreement between changes in EELV and changes in EELI $\left(\mathrm{R}^{2}=0.95\right)$ measuring impedance and lung volume with an open circuit nitrogen washout technique. ${ }^{30}$ The measurement of EIT reflects only a single cross-sectional slice of the lung, so the rest of the organ is ignored. Moreover, thorax shape can contribute as much as lung volume to thoracic impedance. ${ }^{28}$ However, as the system records relative measurements and not absolute impedance distribution, the impedance changes are related to lung volume changes, as chest wall impedance remains relatively constant. Therefore, a reference is needed; in this study we used the tidal impedance variation of the first stable respiratory cycle.

In some subjects the application of the electrode belt may present technical difficulties. We found problems in only one subject, due to the loosening of the contact between 2 electrodes and the skin during the breathing movements. The values derived from these EIT measurements were not reliable, so they were excluded from the analysis.
Moreover, another subject completed only the supine period of the study, so comparison of supine versus prone was done with a sample size of 18 subjects. Finally, the findings of this study are conclusive but limited to healthy subjects. However, to our knowledge, this is the first study about the effect of prone positioning in EELI of subjects with high-flow nasal therapy. Whether similar findings are found in subjects with lung disease should be confirmed in further studies.

\section{Conclusions}

We conclude that the application of noninvasive HFNC in healthy subjects significantly increases their EELI, a fact that suggests an increment of functional residual capacity in both supine and prone positions. HFNC application decreases the breathing frequency in both positions. Prone positioning homogenizes the distribution of $\triangle \mathrm{EELI}$ in these subjects. The evidence of these findings in our population may help to develop new management strategies for hypoxemic patients receiving high-flow oxygen therapy.

\section{REFERENCES}

1. Lund J, Holm-Knudsen RJ, Nielsen J, Føge Jensen PB. [Nasal catheters versus Hudson face mask in oxygen therapy]. Ugeskr Laeger 1996;158(28):4077-4079. Article in Danish.

2. Chatila W, Nugent T, Vance G, Gaughan J, Criner GJ. The effects of high-flow vs low-flow oxygen on exercise in advanced obstructive airways disease. Chest 2004;126(4):1108-1115.

3. Williams AB, Ritchie JE, Gerard C. Evaluation of a high-flow nasal oxygen delivery system: gas analysis and pharyngeal pressures. Intensive Care Med 2006;32(Suppl 1):S219.

4. Dysart K, Miller TL, Wolfson MR, Shaffer TH. Research in highflow therapy. Mechanisms of action. Respir Med 2009;103(10): 1400-1405.

5. Groves N, Tobin A. High flow nasal oxygen generates positive airway pressure in adult volunteers. Aust Crit Care 2007;20(4):126-131.

6. Kubicka ZJ, Limauro J, Darnall RA. Heated, humidified high-flow nasal cannula therapy: yet another way to deliver continuous positive airway pressure? Pediatrics 2008;121(1):82-88.

7. Parke RL, McGuinness SP, Eccleston ML. Nasal high-flow therapy delivers low level positive airway pressure. Br J Anaesth 2009; 103(6):886-890.

8. Parke RL, Eccleston ML, McGuinness SP. The effects of flow on airway pressure during nasal high-flow oxygen therapy. Respir Care 2011;56(8):1151-1155.

9. Tatjana P, Calvano DO, Sill JM, Kemp KR, Chung KK. Use of a high-flow oxygen delivery system in a critically ill patient with dementia. Respir Care 2008;53(12):1739-1743.

10. Tiruvoipati R, Lewis D, Haji K, Botha J. High-flow nasal oxygen vs high-flow face mask: a randomized crossover trial in extubated patients. J Crit Care 2010;25(3):463-468.

11. Roca O, Riera J, Torres F, Masclans JR. High-flow oxygen therapy in acute respiratory failure. Respir Care 2010;55(4):408-413.

12. Sztrymf B, Messika J, Bertrand F, Hurel D, Leon R, Dreyfuss D, Ricard JD. Beneficial effects of humidified high flow nasal oxygen in critical care patients: a prospective pilot study. Intensive Care Med 2011;37(11):1780-1786. 


\section{Effect of High-Flow Nasal Cannula and Body Position on EELV}

13. Sztrymf B, Messika J, Mayot T, Lenglet H, Dreyfuss D, Ricard JD. Impact of high-flow nasal cannula oxygen therapy on intensive care unit patients with acute respiratory failure: a prospective observational study. J Crit Care 2011;27(3):324.e9-e13.

14. Parke RL, McGuinness SP, Eccleston ML. A preliminary randomized controlled trial to assess effectiveness of nasal high-flow oxygen in intensive care patients. Respir Care 2011;56(3):265-270.

15. Holleman-Duray D, Kaupie D, Weiss MG. Heated humidified high-flow nasal cannula: use and a neonatal early extubation protocol. J Perinatol 2007;27(12):776-781.

16. Woodhead DD, Lambert DK, Clark JM, Christensen RD. Comparing two methods of delivering high-flow gas therapy by nasal cannula following endotracheal extubation: a prospective, randomized, masked, crossover trial. J Perinatol 2006;26(8):481-485.

17. Dani C, Pratesi S, Migliori C, Bertini G. High flow nasal cannula therapy as respiratory support in the preterm infant. Pediatr Pulmonol 2009;44(7):629-634.

18. Masclans JR, Roca O. High flow oxygen therapy in acute respiratory failure. Clin Pulm Med 2012;19(3):127-130.

19. Corley A, Caruana LR, Barnett AG, Tronstad O, Fraser JF. Oxygen delivery through high-flow nasal cannulae increase and-expiratory lung volume and reduce respiratory rate in post-cardiac surgical patients. Br J Anaesth 2011;107(6):998-1004.

20. Piehl MA, Brown RS. Use of extreme position changes in acute respiratory failure. Crit Care Med 1976;4(1):13-14.

21. Douglas WW, Rehder K, Beynen FM, Sessler AD, Marsh HM. Improved oxygenation in patients with acute respiratory failure: the prone position. Am Rev Respir Dis 1977;115(4):559-566.

22. Curley MA. Prone positioning of patients with acute respiratory distress syndrome: a systematic review. Am J Crit Care 1999;8(6): 397-405.

23. Malhotra A, Ayas N, Kacmarek RM. Prone positioning of patients in acute respiratory failure. N Engl J Med 2002;346(4):295-297.

24. Sud S, Friedrich JO, Taccone P, Polli F, Adhikari NK, Latini R, et al. Prone ventilation reduces mortality in patients with acute respiratory failure and severe hypoxemia: systematic review and meta-analysis. Intensive Care Med 2010;36(4):585-599.

25. Riedel T, Richards T, Schibler A. The value of electrical impedance tomography in assessing the effect of body position and positive airway pressures on regional lung ventilation in spontaneously breathing subjects. Intensive Care Med 2005;31(11):1522-1528.

26. Hough JL, Johnston L, Brauer SG, Woodgate PG, Pham TM, Schibler A. Effect of body position on ventilation distribution in preterm infants on continuous positive airway pressure. Pediatr Crit Care Med 2012;13(4):446-451.

27. Frerichs I. Electrical impedance tomography (EIT) in applications related to lung and ventilation: a review of experimental and clinical activities. Physiol Meas 2000;21(2):R1-R21.

28. Costa EL, Lima RG, Amato MB. Electrical impedance tomography. Curr Opin Crit Care 2009;15(1):18-24.
29. Riera J, Riu PJ, Casan P, Masclans JR. [Electrical impedance tomography in acute lung injury]. Medicina Intensiva 2011;35(8):509517. Article in Spanish.

30. Hinz J, Hahn G, Neumann P, Sydow M, Mohrenweiser P, Hellige G, Burchardi H. End-expiratory lung impedance change enables bedside monitoring of end-expiratory lung volume change. Intensive Care Med 2003;29(1):37-43.

31. Moerer O, Hahn G, Quintel M. Lung impedance measurements to monitor alveolar ventilation. Curr Opin Crit Care 2011;17(3):260-267.

32. Hahn G, Frerichs I, Kleyer M, Hellige G. Local mechanics of the lung tissue determined by functional EIT. Physiol Meas 1996; 17(Suppl 4A):A159-A166.

33. Adler A, Amyot R, Guardo R, Bates JH, Berthiaume Y. Monitoring changes in lung air and liquid volumes with electrical impedance tomography. J Appl Physiol 1997;83(5):1762-1767.

34. Hinz J, Neumann P, Dudykkevych T, Andersson LG, Wrigge H. Regional ventilation by electrical impedance tomography: a comparison with ventilation scintigraphy in pigs. Chest 2003;124(1): 314-322.

35. Victorino JA, Borges JB, Okamoto VN, Matos GF, Tucci MR, Caramez MP, et al. Imbalances in regional lung ventilation: a validation study on electrical impedance tomography. Am J Respir Crit Care Med 2004;169(7):791-800

36. Marquis F, Coulombe N, Costa R, Gagnon H, Guardo R, Skrobik Y. Electrical impedance tomography's correlation to lung volume is not influenced by anthropometric parameters. J Clin Monit Comput 2006; 20(3):201-207.

37. Richard JC, Pouzot C, Gros A, Tourevieille C, Lebars D, Lavenne F, et al. Electrical impedance tomography compared to positron emission tomography for the measurement of regional lung ventilation: an experimental study. Crit Care 2009;13(3):R82.

38. Pelosi P, Brazzi L, Gattinoni L. Prone position in acute respiratory distress syndrome. Eur Respir J 2002;20(4):1017-1028.

39. Johansson MJ, Wiklund A, Flatebø T, Nicolaysen A, Nicolaysen G, Walther SM. Positive end-expiratory pressure affects regional redistribution of ventilation differently in prone and supine sheep. Crit Care Med 2004;32(10):2039-2044.

40. Gattinoni L, Valenza F, Pelosi P, Mascheroni D. Prone positioning in acute respiratory failure. In: Tobin MJ, editor. Principles and practice of mechanical ventilation, 2nd edition. New York: McGraw-Hill; 2006:1081-1091

41. Bikker IG, Leonhardt S, Bakker J, Gommers D. Lung volume calculated from electrical impedance tomography in ICU patients at different PEEP levels. Intensive Care Med 2009;35(8):1362-1367.

42. Erlandsson K, Odenstedt H, Lundin S, Stenqvist O. Positive endexpiratory pressure optimization using electric impedance tomography in morbidly obese patients during laparoscopic gastric bypass surgery. Acta Anaesthesiol Scand 2006;50(7):833-839.

This article is approved for Continuing Respiratory Care Education credit. For information and to obtain your CRCE

(free to AARC members) visit www.rcjournal.com

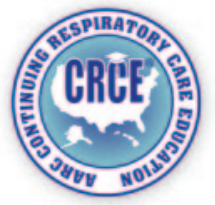

